Trivium: Estudos Interdisciplinares, Ano XIII, Ed. 2. p. 92-102.

http://dx.doi.org/10.18379/2176-4891.2021v2p.92

\title{
Sándor Ferenczi e Melanie Klein: a análise do analista como alicerce da formação
}

Alexandre Patricio de Almeida*

Alfredo Naffah Neto**

\section{Resumo}

Este artigo discute a importância fundamental da análise do analista como o ponto crucial de sua própria formação. Para tanto, apontamos algumas considerações de Freud a respeito do tema, passando, posteriormente, às reflexões de Sándor Ferenczi e suas enriquecedoras contribuições sobre o assunto. Em seguida, descrevemos algumas passagens da biografia de Melanie Klein (Grosskurth, 1992), priorizando o momento do encontro de sua análise pessoal realizada por Ferenczi. Nesse sentido, demarcamos o quanto essa experiência foi indispensável para a construção de Klein como pessoa e, principalmente, como uma ousada (e genial) analista, que consolidou a sua prática com crianças e deixou uma imponente marca na história da psicanálise, transformando sua depressão e melancolia em um grande potencial criativo.

Palavras-chave: ANÁLISE PESSOAL; FREUD; FERENCZI; KLEIN.

\section{Sándor Ferenczi and Melanie Klein: the analyst's analysis as the foundation of the formation}

\begin{abstract}
This article discusses the fundamental importance of analyst analysis as the crux of its own formation. To this end, we point out some considerations of Freud on the subject, passing later to the reflections of Sándor Ferenczi and his enriching contributions on the subject. We then describe some passages from Melanie Klein's biography (Grosskurth, 1992), prioritizing the timing of the meeting of his personal analysis by Ferenczi. In this sense, we point out how indispensable this experience was for Klein's construction as a person and, especially, as a bold (and ingenious) analyst, who consolidated his practice with children and left an imposing mark on the history of psychoanalysis, transforming his depression and melancholy in great creative potential.
\end{abstract}

Keywords: PERSONAL ANALYSIS; FREUD; FERENCZI; KLEIN.

\section{Sándor Ferenczi et Melanie Klein: l'analyse de l'analyste comme fondement de la formation}

\section{Résumé}

Cet article traite de l'importance fondamentale de l'analyse par les analystes au cœur de sa propre formation. À cette fin, nous rappelons quelques considérations de Freud sur le sujet, puis des réflexions de Sándor Ferenczi et de ses contributions enrichissantes sur le sujet. Nous décrivons ensuite quelques passages de la biographie de Melanie Klein (Grosskurth, 1992), en donnant la priorité au moment de la réunion de son analyse personnelle par Ferenczi. En ce sens, nous soulignons combien cette expérience était indispensable pour la construction de

\footnotetext{
* Psicanalista. Doutor e Mestre pelo Programa de Psicologia Clínica da PUCSP. Pesquisador bolsista CNPq. ORCID ID: http://orcid.org/0000-0002-6429-8083

E-mail: alexandrepatriciodealmeida@yahoo.com.br
}

\footnotetext{
** Psicanalista. Professor titular do Programa de Estudos Pós-graduados em Psicologia Clínica da PUCSP. ORCID ID: https://orcid.org/0000-0002-1918-7878 
Klein en tant que personne et, en particulier, en tant qu'analyste audacieux (et ingénieux), qui a consolidé sa pratique avec les enfants et laissé une marque imposante dans l'histoire de la psychanalyse, transformant sa dépression et la mélancolie au grand potentiel créatif.

Mots-clés: ANALYSE PERSONNELLE; FREUD; FERENCZI; KLEIN.

\section{Introdução}

Em uma das partes que compõem o escrito técnico de Freud publicado, originalmente, em 1912 e intitulado "Recomendações ao médico para o tratamento psicanalítico", somos apresentados à seguinte afirmação: "Há anos, quando perguntado sobre como nos transformamos em analistas, respondi: através da análise dos próprios sonhos. Certamente, essa preparação é suficiente para muitas pessoas, mas não para todas que querem aprender a análise" (Freud, 1912/2017, p. 100). Durante anos, esse texto de Freud foi uma espécie de "escrito sagrado" para muitos analistas, orientando a conduta de alguns, ao mesmo tempo que enrijecia a prática analítica de outros - quando utilizado como um manual. Hoje, todavia, sabemos que a psicanálise não ocorre dentro dos mesmos formatos da época freudiana. Temos, portanto, outro fazer clínico, com diferentes demandas e que, inevitavelmente, exigem do analista uma formação mais ampla e contínua - apesar de as diretrizes éticas descritas por Freud neste texto ainda se manterem relevantes.

Neste mesmo artigo de 1912, Freud já apresenta ao leitor, porém, uma das ideias que pretendemos sustentar no decorrer de nosso trabalho: a necessidade imprescindível da análise pessoal do futuro candidato à analista. Citamos o autor:

Para tanto, não basta ele [futuro analista] ser uma pessoa razoavelmente normal; podese, antes, exigir que ele tenha se submetido a uma purificação (Purifizierung) psicanalítica e que tenha tomado conhecimento daqueles complexos próprios, adequados para atrapalhá-lo na absorção daquilo que lhe é apresentado pelo analisando. A bem da verdade, não se pode duvidar do efeito desqualificante de tais defeitos próprios; cada recalque não resolvido do médico corresponde, de acordo com uma expressão precisa de Wilhelm Stekel, a um "ponto cego" em sua percepção analítica (Freud, 1912/2017, p. 99-100, colchetes nossos).

Por este âmbito, entendemos o que Freud quis dizer nas entrelinhas com a expressão "análise dos próprios sonhos", ou seja, o candidato a analista deve-se atirar na imensidão do desconhecido, ter a coragem de olhar-se no espelho e defrontar-se com o reflexo de suas próprias limitações, medos e frustrações, pois, será somente após esta imersão longínqua e dolorosa, que podemos nos colocar na condição de tentar oferecer nossa escuta psicanalítica a alguém na esperança de acolher o indizível e as cicatrizes da alma, produzindo ressignificações ao sofrimento do sujeito que nos procura.

Sabemos, porém, que não somos todos nós que temos as habilidades freudianas de analisar os nossos próprios materiais inconscientes. Por isso, a ousadia de tentar percorrer o caminho sozinho, corre o risco de se transformar numa verdadeira catástrofe, onde poderá se dar qualquer processo formativo, menos o psicanalítico em sua real essência. Talvez, tenha sido essa condição que fez Freud mudar a sua concepção a respeito das bases que estabeleciam a formação em psicanálise.

Atualmente, conhecemos como "tripé" as três regras fundamentais que estruturam o longo e árduo processo que atravessa e sustenta a formação psicanalítica. Trata-se, grosso modo, do estudo aprofundado da teoria; da supervisão clínica realizada por um analista mais experiente; e, principalmente, a própria análise do futuro candidato ao exercício dessa profissão 
que Freud considerava "impossível" de ser plenamente exercida. No texto "A análise finita e a infinita", publicado nos anos finais de sua vida (originalmente em 1937), Freud afirmará:

Detenhamo-nos um pouco aqui, para garantirmos ao analista nossa sincera empatia e que, ao exercer a sua atividade, sentimos com ele a dificuldade em cumprir exigências tão duras. É quase como se o analisar fosse aquela terceira das profissões "impossíveis", em que se tem a certeza de antemão do resultado insuficiente. As outras duas conhecidas há muito mais tempo, são o educar e o governar. Aparentemente, não podemos exigir que o futuro analista seja um ser completo antes de se ocupar com a análise, ou seja, que apenas pessoas de uma completude tão perfeita e tão rara possam se dedicar a essa profissão (Freud, 1937/2017, pp. 355-356).

Neste trabalho, diferente daquilo que foi proposto no texto técnico de 1912, o problema lançado por Freud se dirige às questões relacionadas não somente ao âmbito da formação profissional, mas, sobretudo, ao processo de construção pessoal do analista, que nada mais é, do que um ser humano, como qualquer outro, que traz em seu interior dores, angústias, defesas, inseguranças e vulnerabilidades, encobertas pelo mar profundo do inconsciente que só serão encontradas mediante a própria busca desse indivíduo. Ser psicanalista, portanto, significa ter a coragem de aventurar-se, primeiramente, nas profundidades de seus próprios oceanos, antes de se atrever a penetrar o território desconhecido do outro. Somente passando pela experiência de análise que o analista conseguirá desenvolver as habilidades de escuta, empatia e manejo relacionadas ao tratamento psicanalítico. Sem vivenciar esse complexo aprendizado, a tentativa de tornar-se analista perde-se, antes mesmo de ser iniciada.

Além disso, a análise do analista terá como intuito, explorar e expandir suas dificuldades, rompendo suas resistências, liberando-o das algemas que o prendem em sua real dimensão conflitiva e, por conseguinte, existencial. Analisar-se é, sem sombra de dúvidas, uma tarefa indispensável ao candidato que almeja empreender-se às inconsistências do impossível como bem nos disse Freud. Aliás, achamos conveniente, aqui, citá-lo mais uma vez:

Onde e como o pobre coitado [candidato à analista] poderá adquirir aquela habilitação ideal, necessária em sua profissão? A resposta será: na própria análise, com a qual começa a preparação para a sua atividade futura. Por razões práticas, esta só poderá ser breve e incompleta; a sua finalidade principal é possibilitar um juízo ao professor para avaliar se o candidato pode ser aprovado para continuar a formação. O seu trabalho estará terminado quando trouxer para o aprendiz a convicção segura da existência do inconsciente, quando lhe transmitir as autopercepções - normalmente indignas de credulidade - ao aflorar o recalcado e, por fim, quando lhe mostrar, a partir de uma primeira amostra, a técnica que só se consolida na atividade analítica (Freud, 1937/2017, p. 356, colchetes nossos).

No entanto, Freud afirma que apesar de ser indispensável ao processo formativo, a análise por si só, não é o suficiente - nesse âmbito concordamos plenamente com ele. Ora, o que queremos dizer com isso? A análise não deve ser utilizada, unicamente, com o objetivo de formação profissional, mas deve partir do próprio desejo do futuro analista em querer descobrirse como ser humano - em todas as suas múltiplas instâncias. Capacidade essa reconhecida como a mais libertadora e gratificante de uma boa análise.

Espera-se, portanto, que "a partir das motivações recebidas na própria análise que elas não se esgotem com o seu término, mas que os processos de reformulação do Eu (Ichumarbeitung) continuem espontaneamente no analisando" (Freud, 1937/2017, p. 356). 
Desse modo, as novas experiências adquiridas durante a análise do candidato, devem ser utilizadas a fim de lhe propiciar novos sentidos à sua própria subjetividade. É esse movimento interno (e, por que não?, externo) que possibilita ao futuro psicanalista dimensionar o seu verdadeiro exercício clínico, buscando sempre o apoio, em sua própria análise, como um recurso de amparo perante as situações desafiantes, derivadas dos atendimentos e da prática clínica - seja ela exercida dentro ou fora do consultório.

"Por um lado, toda formação implica uma transmissão. Por outro lado, a experiência de vida não resiste tanto à transmissão, mas à recepção. A experiência de um é sempre apenas a experiência de um" (Mandelbaum, 2013, p. 138). Logo, ninguém pode assumir a experiência do outro, que é, fundamentalmente, única e singular. Por isso, a necessidade indispensável de se conceber a análise como um processo formativo. A análise pessoal do futuro analista rompe os véus encobridores da transmissão, pois toca o mais arcaico que guardamos no interior de nós mesmos - arcaico que também encontraremos em nossos pacientes.

A análise de si próprio não se limita apenas à intelectualidade do processo, pois o papel dela é o de, muitas vezes, desconstruir para construir e, nessa ótica, ela ultrapassa as barreiras de qualquer transmissão, pois consiste em uma experiência pessoal. A experiência está incluída em outro segmento, a nosso ver, ela se constitui da noção de liberdade humana. Emerge do "reconhecer-se" como um ser dotado de existência e, portanto, convocado a viver. É uma abertura para a qual colabora a responsabilidade na estruturação de si mesmo - território privilegiado da psicanálise. Neste sentido, quando nos referimos ao tema da liberdade, não estamos, de modo algum, fazendo alusão a um processo formativo psicanalítico solto e sem direcionamento - mesmo porque isso vai contra todas as ideias desenvolvidas por Freud -, mas, sim às mudanças intrapsíquicas ocasionadas ao próprio terapeuta que passa por um período significativo de análise pessoal, ou seja, à ideia de que a análise pessoal, ao iluminar aspectos obscuros da psique humana, aumenta a liberdade na capacidade de fazer escolhas significativas, ao longo da vida, podendo arcar com os ganhos e as perdas decorrentes. Além disso, ao percorrer o caminho do autoconhecimento, o jovem analista poderá, entre os diversos percalços enfrentados, ir de encontro à sua verdadeira essência, evitando que aspectos mal elaborados de seu campo subjetivo invadam o território reservado ao par paciente-analista. Citamos Freud:

Não causaria espanto se através do trabalho com todo o recalcado, que luta por satisfação na alma humana, também despertássemos no analista aquelas demandas pulsionais que ele do contrário poderia manter reprimidas. Esses também são os "perigos da análise", que não ameaçam o parceiro passivo, mas sim o ativo na situação analítica, e não deveríamos deixar de enfrentá-los (Freud, 1937/2017, p. 357).

A análise do analista deve ser, portanto, uma prática constante. Freud também pensou nisso e afirmou que "todo analista, periodicamente, por exemplo, a cada cinco anos, deveria voltar a se tornar objeto da análise, sem se envergonhar desse passo. Isso significaria, portanto, que também a própria análise se transformaria de tarefa finita em tarefa infinita" (Freud, 1937/2017, p. 357). Nesse quesito, o processo analítico do psicanalista é mais que uma etapa de sua formação, é uma conduta permanente - tais como o estudo da teoria e a supervisão. Talvez seja essa, a dimensão implícita que Freud quis nos dizer com o termo "impossível". Afinal, buscar compreender os emaranhados de nossas entranhas psíquicas é uma tarefa para toda a vida.

\section{As contribuições de Ferenczi sobre a análise do analista}

"Ferenczi não é somente um dos pioneiros da psicanálise, ele é, depois de Freud, o protagonista mais importante dos primórdios de sua história. Junto com Freud, foi um dos

Trivium: Estudos Interdisciplinares, Ano XIII, Ed. 2. p. 92-102. 
grandes militantes da causa psicanalítica" (Pinheiro, 2016, p. 179). O que orientava a clínica de Ferenczi era a ética e o compromisso com os seus pacientes. Questionou o lugar do analista e formulou a hipótese de que o trabalho psicanalítico poderia ser muitas vezes, um mero instrumento a serviço de suas próprias resistências e dificuldades. Nesse sentido, o analista húngaro priorizou a análise do próprio psicanalista como a base central do tripé formativo e, por esta via, retomou a importância da pessoalidade do profissional que pretende exercer a psicanálise pessoalidade que ficou "perdida" no campo psicanalítico da época devido às restrições impostas pelo positivismo científico, ao qual se prendeu o próprio Freud, diga-se de passagem, na

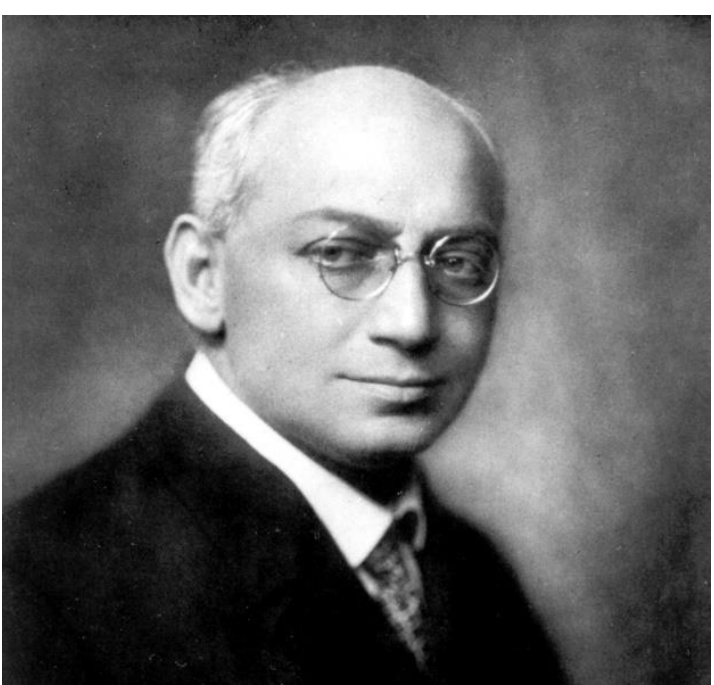

Sándor Ferenczi (1873-1933) busca incansável do reconhecimento da psicanálise como uma ciência. Citamos Ferenczi:

Entretanto, houve e ainda há no interior da técnica psicanalítica muitas coisas que davam a impressão de tratar-se de algo individual, pouco definível com palavras; em primeiro lugar, o fato de que, neste trabalho, a importância que parecia ser atribuída à "equação pessoal" era muito maior da que deveríamos, por outro lado aceitar na ciência. O próprio Freud, em suas primeiras comunicações sobre a técnica, deixava o campo livre para outros métodos de trabalho em psicanálise, a par do seu. É verdade que essa declaração data antes da época em que se cristalizou a segunda regra fundamental da psicanálise, isto é, que quem quer analisar os outros deve, em primeiro lugar, ser ele próprio analisado (Ferenczi, 1928/2011, pp. 30-31, grifos do autor).

Desse modo, ao enfatizar a importância da necessidade da análise do analista, Ferenczi retomou a matriz ideológica de pessoalidade existente nas origens do pensamento psicanalítico, mas que acabou se perdendo com o tempo (e o excesso de racionalidade). O processo de análise, para o autor húngaro, possibilitava a construção de uma estrutura que ele considerou ser crucial ao processo terapêutico: o tato. Em outras palavras, o tato é a faculdade de sentir com (Einfühlung), advinda da descoberta remanescente de nosso próprio eu. Por meio dela, conseguimos tornar presentes as associações possíveis ou prováveis do paciente, já que também foram vivenciadas em nossa experiência analítica.

"Esse sentimento nos impedirá de estimular a resistência do paciente, de maneira inútil ou intempestiva; por certo, não é dado à psicanálise poupar o paciente de todo o sofrimento; com efeito, aprender a suportar um sofrimento constitui um dos resultados principais da psicanálise" (Ferenczi, 1928/2011, p. 32). O tato não significa, de forma alguma, ser complacente e bondoso para o paciente, mas ter um grau de empatia para sentir com ele as ressonâncias de suas dores e de seu sofrimento. O que nos possibilitará pensar em intervenções que sejam mais eficazes e significativas.

Ao falar de tato, empatia e, com isso, priorizar a análise do analista no percurso de formação, Ferenczi tocará em várias feridas narcísicas que tangem à postura do psicanalista. Ele dirá, por exemplo, que "nada de mais nocivo em análise do que uma atitude de professor ou mesmo médico autoritário" (Ferenczi, 1928/2011, p. 336). Por essa razão, irá criticar o caráter afirmativo e ortodoxo das interpretações, salientando a humildade de reconhecermos os nossos erros, sem delegarmos, exclusivamente, ao paciente a posição de resistência, responsabilizando-o pelo fracasso do tratamento. "A modéstia do analista não é, portanto, uma 
atitude aprendida, mas a expressão da aceitação dos limites do nosso saber" (Ferenczi, 1928/2011, p. 36, grifos do autor).

Com esse modo de compreender a clínica, Ferenczi colocará em primeiro plano a segunda regra fundamental da psicanálise: a análise do analista. É somente ela que irá amenizar as nossas onipotências infantis, o nosso implacável narcisismo e possibilitará a nossa capacidade de desenvolver o tato, compreendendo a angústia do outro, ao escutá-la em sua totalidade. $\mathrm{O}$ autor condena a postura hipócrita de neutralidade dos analistas que se dizem intocáveis perante o sofrimento alheio. Aliás, essa atitude fria, em sua concepção, apenas servirá como um fator "retraumatizante" da situação original causadora do trauma.

"Em de janeiro de 1928, Freud cumprimentou Ferenczi por seu artigo 'Elasticidade da técnica psicanalítica' [cujos trechos foram citados por nós]. Segundo ele, um perfeito complemento ao seu 'Recomendações aos médicos que exercem a psicanálise' (Freud, 1912)" (Pinheiro, 2016, p. 101, colchetes nossos). Freud também demonstrou, contudo, certa preocupação com relação à interpretação que o leitor pudesse fazer de sua ideia de "tato", como se essa noção pudesse conferir uma liberdade excessiva ao analista iniciante. Ferenczi respondeu a essa carta dizendo que a análise dos analistas seria o maior recurso para se evitar essa interpretação equivocada, o que comprova a sua posição sobre a necessidade do analista realizar a sua própria análise.

É curioso, no entanto, que um psicanalista que lançou tantas reflexões a respeito da análise pessoal do candidato ao exercício psicanalítico tenha sido o terapeuta de (ninguém menos) que Melanie Klein. Essa autora que mudou a concepção a respeito da psicanálise com crianças e expandiu, consideravelmente, as ideias freudianas, foi paciente de Sándor Ferenczi por um período de sete anos (1914-1921). Serão as influências desse período de análise para a formação pessoal de Klein que iremos discutir nos próximos itens de nosso texto.

\section{As influências de Ferenczi sobre a pessoa ${ }^{1}$ de Klein}

Salientamos, desde o início desse artigo, a importância da própria análise do analista para a sua constituição pessoal e, por conseguinte, profissional. Nosso intuito, dessa parte em diante do trabalho, será o de explorar - a fim de permitir maiores reflexões do leitor sobre o tema - as influências desse rico período correspondente ao encontro de Klein com Ferenczi, que ocorreu em Budapeste de 1914 a 1921. Para tanto, delinearemos um breve percurso biográfico da autora que se faz indispensável para sustentarmos tal discussão.

Melanie Reizes nasceu em Viena, no dia 30 de março de 1882. Filha de Moriz Reizes, médico e dentista, e Libussa Deustsch, dona de casa e proprietária de um pequeno comércio. Melanie era a filha mais nova de quatro filhos. Apesar de não

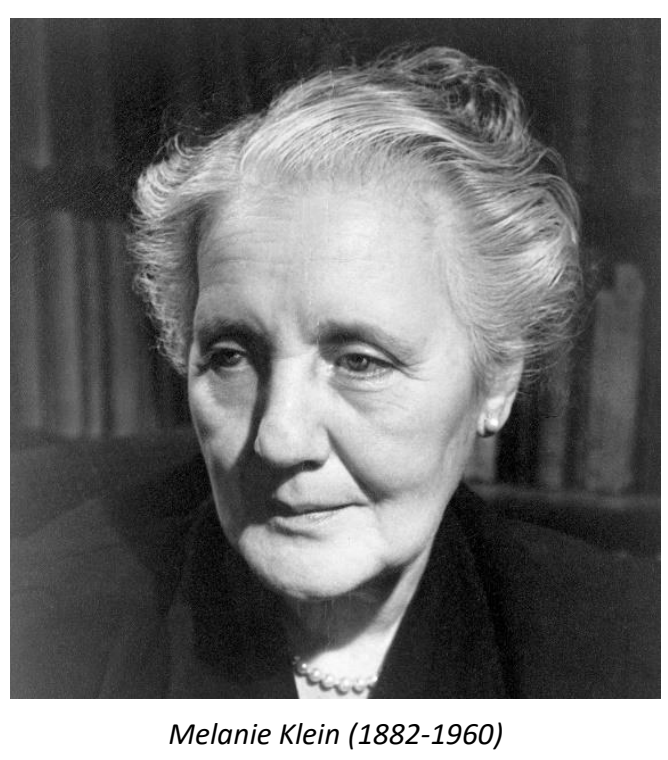
possuir uma condição financeira tão favorável, a família Reizes vivia imersa num ambiente cultural rico e criativo. Melanie sonhava em ser médica como o pai e um dia, quiçá, poder salvar vidas.

Quando Klein tinha apenas quatro anos, perde sua irmã Sidonie, que morreu de "escrófula em 1886 [...]. Essa foi a primeira de uma longa série de mortes que pontuaram a vida de Melanie Klein, cada uma delas reativando o medo, a dor e a perplexidade" (Grosskurth, 1992, p. 27). Posteriormente, perde o seu pai aos 18 anos e, aos vinte, perde o seu querido irmão 
Emanuel. Essas experiências de luto e sofrimento psíquico marcaram, significativamente, a vida e a obra de Melanie Klein.

Em 1903, Melanie casa-se com Arthur Klein (de quem herda o sobrenome). Arthur era o melhor amigo do seu irmão Emanuel, recém-falecido, além de ser um engenheiro químico bem sucedido - o que garantiria certa estabilidade financeira ao próprio futuro de Melanie. $\mathrm{O}$ casamento precoce impediu-a, porém, de se tornar a grande médica que sempre sonhara - vindo a ser a maior razão de suas frustações.

Em 1904, aos 24 anos, nasce sua filha Melitta Klein. A profissão de Arthur demandava contínuas mudanças de cidade, que Melanie se via na obrigação de acompanhar (mesmo sendo contra a sua vontade). Por conta disso e das suas variações de humor, um tanto quanto patológicas, Klein cuidou de Melitta até os sete meses, deixando a filha aos cuidados da mãe (Libussa) e de babás ${ }^{2}$.

Seu segundo filho, Hans, nasce em 1907. Logo após, Klein apresenta um terrível quadro de depressão. Libussa vai morar com a família Klein para ajudar no cuidado das crianças. A rivalidade entre Klein e Libussa é intensa, já que sua mãe possuía uma personalidade bastante difícil, com condutas intrusivas e autoritárias. "A combinação de Libussa e Melanie na mesma casa provocava uma catástrofe. Duas vontades fortes opunham-se [...]. Mãe e filha estavam sempre se desentendendo quanto à educação das crianças e à administração da casa" (Grosskurth, 1992, p. 69).

Em 1910, a família muda-se para Budapeste, onde Melanie toma contato com a obra de Freud. Lê, em 1914, o texto "Sobre os sonhos" (Über den Traum) do livro "A interpretação dos sonhos" - publicado, originalmente, em 1900 e considerado o grande marco da psicanálise. Klein tem uma breve recuperação de suas crises depressivas em 1912, mas que, infelizmente, durou muito pouco. 1913 e 1914 foram anos de terrível tensão. Perto do Natal de 1913, ela descobriu que estava grávida, reagindo muito mal à ideia de ter outro filho quando já passara dos trinta anos. Erich nasceu em $1^{\circ}$ de julho de 1914. Obviamente, Libussa ficou encantada com o nascimento do neto, mas suas condições de saúde já não lhe permitiam o exercício de certos cuidados.

No final de outubro do mesmo ano, Melanie e Arthur levaram Libussa a uma clínica para tirar radiografias. Os exames não apontaram qualquer sinal de câncer. Quase imediatamente, porém, Libussa adoecera por uma grave bronquite. Ao passar dos dias, seu estado de saúde foi piorando - o que sinalizou a sua eminente morte. Melanie descreve, em sua autobiografia, "de que fora acometida por um enorme sentimento de culpa, de que podia ter feito mais por ela" (Grosskurth, 1992, p. 75). Ajoelhou-se no leito da mãe e pediu-lhe perdão. Ao ver o gesto da filha, Libussa disse: "Não se entristeça, não chore; em vez disso lembre-se de mim com amor" (Grosskurth, 1992, p. 75). Ela faleceu em 6 de novembro de 1914.

Provas biográficas demonstram, no entanto, que Klein nunca conseguiu chegar a um acordo entre "realidade e fantasia" a respeito do verdadeiro sentimento que ela possuía por sua mãe. Em sua autobiografia, Libussa é tão idealizada que se torna irreconhecível. "Seria isso a defesa de Melanie contra o desespero metafísico que sentia por não ter agora um modo de fazer uma reparação a Libussa, morta há muito tempo?” (Grosskurth, 1992, p. 69). Nesse sentido, a última frase que encerra o seu prestigiado artigo "Amor, culpa e reparação", de 1937, ilustra, concretamente, as suas próprias questões emocionais:

[...] ter uma boa relação com nós mesmos é uma condição essencial para o amor, a tolerância e a sabedoria para com os outros. Como procurei demonstrar, essa boa relação com nós mesmos se desenvolve em parte de uma atitude amistosa, compreensiva e amorosa para com as outras pessoas, ou seja, aqueles que tiveram importância para nós no passado. Nossa relação com essas pessoas se torna parte de nossa mente e de nossa personalidade. Se, no fundo da nossa mente inconsciente, conseguimos liberar até certo 
ponto os sentimentos que temos pelos nossos pais do ressentimento, se os perdoamos pelas frustrações que tivemos que sofrer, então podemos ficar em paz com nós mesmos e amar os outros no verdadeiro sentido da palavra (Klein, 1937/1996, p. 384).

Idealizar sua mãe com o auxílio de mecanismos reparadores talvez tenha sido a única saída encontrada por Klein para lidar com os seus conflitos internos e amenizar os seus ressentimentos em relação a Libussa. Frutos colhidos, muito provavelmente, de um processo transformador advindo de sua análise pessoal que teve início, em 1914, com Sándor Ferenczi.

Quando Melanie Klein conheceu Ferenczi, ele era há alguns anos o amigo mais estimado de Freud (que o chamava de "meu amado filho") e ocupava uma posição importante na Sociedade Psicanalítica de Budapeste. Além disso, Freud mandava para Ferenczi cada manuscrito antes de publicá-lo, de modo que estar próximo ao analista húngaro representava um grande privilégio.

Melanie começou a fazer análise, a princípio, em virtude de uma depressão aguda, intensificada pela morte de sua mãe. A atenção e o cuidado empático de Ferenczi foram cruciais ao processo curativo de Klein. Ele tratava seus pacientes com delicadeza, como uma criança carente, necessitada de atenção. Tal atenção concentrada à dor do outro era, sem dúvida alguma, o que Melanie Klein almejava depois dos longos anos em que não tivera alguém para abrir o seu coração. Por sua vez, "ela trazia um material valioso para o estudo clínico de Ferenczi" (Grosskurth, 1992, p. 83).

Em sua autobiografia, Melanie Klein explicou a origem do trabalho de toda sua vida e o sentido de sua paixão pelo desenvolvimento psíquico infantil, agradecendo a Ferenczi por sua compreensão e apoio:

Durante minha análise com Ferenczi, ele chamou minha atenção para o dom real que eu tinha de compreender as crianças e para o interesse que eu revelava por elas, e me incentivou sem restrições em minha intenção de me dedicar à análise e em particular à análise de crianças. Nessa época, eu tinha, é claro, três filhos meus. [...] Não descobrira [...] que a educação [...] podia abranger toda a compreensão da personalidade e, por conseguinte, ter a influência que se desejaria que tivesse. Sempre tive a sensação de que por trás estava algo que eu não conseguia atender (Grosskurth, 1992, pp. 84-85).

Ferenczi também incentivou outras colegas a concentrar-se na análise de crianças - Ada Schott e até Anna Freud. Parecia, na concepção dele, uma atividade apropriada a ser exercida por uma mulher; e, "no caso de Melanie, é possível que Ferenczi lhe tenha sugerido a observação rigorosa de crianças como um meio de aproximar-se do âmago de seus problemas" (Grosskurth, 1992, p. 85). Em outras palavras, entender as raízes do psiquismo infantil poderia possibilitar a Klein, na visão de Ferenczi, a compreensão subjetiva de suas próprias dificuldades, mas isso só foi possível, pois ela mesma havia passado por um significativo período de análise.

Melanie Klein ainda estava em análise com Ferenczi em 1919 - talvez, um dos períodos mais decisivos ao seu futuro. "Michael Balint lembrava-se de estar sentado na sala de espera dele, aguardando para discutir uma conferência que o ouvira fazer na universidade, quando a porta do consultório se abriu e por ela saiu Melanie Klein aos prantos" (Grosskurth, 1992, p. $85)$.

Ainda em julho de 1919, Klein apresentou, sob o incentivo de Ferenczi, um relato da análise de uma criança à Sociedade Húngara, depois do qual foi imediatamente admitida como membro desta - dada a qualidade do artigo. Esse trabalho foi publicado no ano seguinte, na Internationale Zeitschrift für Psychoanalyse $e^{3}$, sob o título original "Der Familienroman in statu 
ascendi". O material relata a análise de seu próprio filho Erich, que teve sua identidade encoberta por questões éticas.

Melitta e Hans haviam sido criados em grande parte sob a supervisão da avó; mas, "depois que Melanie Klein descobriu a psicanálise, Erich foi submetido à observação mais intensa, desde pelo menos os seus três anos de idade" (Grosskurth, 1992, p. 86) - tornando-se, futuramente, o filho mais próximo, carinhoso e companheiro de Klein. Esse primeiro artigo kleiniano pretendeu mostrar os resultados milagrosos obtidos quando uma mãe cria o filho de acordo com os conceitos psicanalíticos esclarecidos. Ao contrário de Anna Freud, Klein acreditava, desde o início, que a criança deveria ser analisada como um adulto, ou seja, sem qualquer sugestão ou interferência educacional - fatores que colaboraram para a construção de um novo paradigma que a tornou reconhecida mundialmente.

Em 1920, no $6^{\circ}$ Congresso Internacional de Psicanálise, em Haia, Klein conhece Karl Abraham, seu futuro analista e, também, grande protetor e incentivador. A convite de Abraham, Melanie muda-se para Berlim, em 1921, onde abre seu consultório para realizar o atendimento psicanalítico de crianças. Em 1922, devido ao valor de suas descobertas e produções intelectuais, Klein torna-se membro da Sociedade Psicanalítica de Berlim. A ascensão profissional e sua estabilidade emocional foram os agentes propulsores que a incentivaram de vez a divorciar-se de Arthur. Encorajada por suas motivações, Klein encerra um ciclo de frustações e infelicidade que sustentava o seu casamento.

Em 1926, após a morte precoce de Abraham (que ocorreu no ano anterior), Klein percebe-se totalmente desolada e solitária em Berlim e, convidada por Ernest Jones, muda-se para a Inglaterra neste mesmo ano. Em 1927, Melanie é eleita membro pleno da Sociedade Britânica de Psicanálise. Nesse período, suas ousadas teorias sobre o mundo arcaico e primitivo a respeito do psiquismo infantil já atraía diversos admiradores.

Klein viveu em Londres de 1926 até 1960, quando veio a falecer, por intercorrência de um câncer. Lá, o seu legado foi erguido e solidificado. Tornou-se uma das grandes fundadoras do que, por muitos anos, ficou conhecida como a Escola Inglesa de Psicanálise. Seu jeito irreverente e revolucionário de praticar a clínica e compor as suas teorias deixou marcas permanentes na ciência criada por Freud.

Paremos por aqui, mesmo porque a ideia central desse artigo não é a de descrever toda a biografia de Melanie Klein, mas sim apresentar os detalhes do período de vida correspondente à sua análise com Sándor Ferenczi. Para o leitor que se interessar pelos bastidores da vida pessoal dessa grande analista, recomendamos o estudo de sua biografia cuidadosamente escrita por Phyllis Grosskurth, publicada no Brasil com o título "O Mundo e a Obra de Melanie Klein".

\section{Algumas palavras finais}

Melanie Klein poderia ter sido como qualquer outra mulher de sua época: casada precocemente, tendo que assumir as responsabilidades de uma família; frustrada em relação aos seus próprios sonhos e por não poder satisfazer as suas ambições profissionais; amargurada, ancorando-se nas lamúrias de uma vida infeliz; depressiva e isolada do mundo social, ao passo em que se isolava, também, de si própria. De forma alguma, porém, contentou-se com a mediocridade de um destino infeliz. Ao ler o texto de Freud, ficou apaixonada pela psicanálise, o que a fez buscar um tratamento psicanalítico, com o intuito de amenizar o seu sofrimento.

Foi por meio de sua própria análise que Melanie pôde descobrir com o auxílio de seu analista, Sándor Ferenczi, a sua vocação para tornar-se, ela mesma, psicanalista. Quando criança, Klein almejava ser médica e salvar vidas, tal como fazia o seu pai. Apesar de nunca se ter tornado médica, podemos dizer que, simbolicamente, a sensibilidade clínica desta autora, cuja história de vida foi tão fascinante, permitiu-lhe aproximar-se das agonias mais primitivas 
do outro, auxiliando-o a encontrar as chaves que liberavam os demônios internos que os aprisionava em estados de agonia e desamparo.

Podemos, pois, afirmar que sem o mínimo de ressonância empática com o sofrimento do paciente não é possível conduzir uma análise. "Melanie Klein se apropria profundamente dessa empatia em sua escuta analítica, sendo herdeira, portanto, de Ferenczi nesse aspecto" (Cintra \& Ribeiro, 2018, p. 28). Por outro lado, é possível dizer que a compreensão do aparelho psíquico em Freud, Abraham e, por sua vez, em Klein é predominantemente intrapsíquico - ou seja, a importância dada aos aspectos do mundo interno e às fantasias do sujeito por esses autores é grandiosa; ao passo que em Ferenczi, Balint e Winnicott, o psiquismo passou a ser pensado de modo intersubjetivo - isto é, constituído na trama de relações com os outros sujeitos e, principalmente, com o ambiente.

Conforme tentamos deixar em evidência, desde o início da escrita deste texto, o nosso objetivo, aqui, não é o de apresentar as influências teóricas de Ferenczi sobre Klein - mesmo porque, como já dissemos, acreditamos que Klein foi muito mais influenciada em seu campo teórico pelo pensamento de Abraham. A nossa proposta se constitui pela pretensão de discutir o quanto a análise do analista é essencial à sua própria formação. No caso de Melanie, foi Ferenczi que a tornou psicanalista. O poder de sua análise foi tão libertador, que ela conseguiu soltar-se das amarras de uma vida frustrada e depressiva, tornando-se uma das maiores psicanalistas da história.

É em nossa própria análise que, muitas vezes, conseguimos perceber em nós algo em que comum que, também, atinge os nossos pacientes. É desse tato que Ferenczi falava - ou seja, da disposição em sentir com. Mas, como "sentir com", se nunca se pôde viver tal experiência em si próprio? É inadmissível empreender uma formação psicanalítica sem antes o candidato ter vivido a psicanálise em sua própria pele. São estas as linhas que se cruzam entre Ferenczi e Klein. Com ele, a analista de crianças aprendeu a escutar, dirigindo sua atenção às forças produtoras do conflito e da dor, para, apenas num segundo momento, discernir o caminho de desconstrução das defesas, das formas de ser que impedem, mutilam e inibem a nossa verdadeira razão de existir.

Mais que um item do tripé da formação, acreditamos, por fim, que a análise do futuro analista seja essencial para inseri-lo, de vez, nas tramas nebulosas que compõe o tecido estruturante de nosso inconsciente.

Terminamos o nosso texto com uma citação da própria Melanie Klein, onde fica explícito o seu sentimento de gratidão a Ferenczi - seu primeiro e grande analista que não só a salvou do despenhadeiro da depressão, mas lhe deu um novo sentido à vida ao lhe apresentar as vicissitudes que transcendem o ofício da arte que é psicanalisar.

Tenho muito que agradecer a Ferenczi. Uma coisa que ele me transmitiu e reforçou em mim foi a convicção da existência do inconsciente e de sua importância para a vida psíquica. Também gostei de ter contato com um homem que possuía dons extraordinários. Ele tinha um traço de genialidade (Grosskurth, 1992, p. 84).

\section{Referências}

Cintra, E. M. U. \& Ribeiro, M. F. R. (2018). Por que Klein? São Paulo: Zagodoni.

Cintra, E. M. U. \& Figueiredo, L. C. (2010). Melanie Klein. Estilo e Pensamento. São Paulo: Escuta. (2a. Ed.).

Ferenczi, S. (2011). A elasticidade da técnica psicanalítica. In: Obras completas de Sándor Ferenczi, vol. 4. São Paulo: Editora WMF Martins Fontes. (Original publicado em 1928).

Trivium: Estudos Interdisciplinares, Ano XIII, Ed. 2. p. 92-102. 
Freud, S. (2017). Recomendações ao médico para o tratamento psicanalítico. In: Fundamentos da clínica psicanalítica, Obras incompletas de S. Freud, vol. 6. Belo Horizonte: Autêntica Editora. (Original publicado em 1912).

Freud, S. (2017). A análise finita e a infinita. In: Fundamentos da clínica psicanalítica, Obras incompletas de S. Freud, vol. 6. Belo Horizonte: Autêntica Editora. (Original publicado em 1937).

Grosskurth, P. (1992). O Mundo e a Obra de Melanie Klein. Rio de Janeiro: Imago.

Klein, M. (1937). Amor, culpa e reparação. In: Amor, culpa e reparação e outros trabalhos (1921-1945). Rio de Janeiro: Imago, 1996.

Mandelbaum, E. (2013). Notas sobre a formação em psicanálise. In: Duvidovich, E. (org.). Diálogos sobre formação e transmissão em psicanálise. São Paulo: Zagodoni.

Naffah Neto, A. (2019). Melanie Klein e Winnicott: porta-vozes das tradições de Abraham e Ferenczi. In: Cintra, E. M. U. \& Ribeiro, M. F. R. Melanie Klein na psicanálise contemporânea: teoria, clínica e cultura. São Paulo: Zagodoni.

Pinheiro, T. (2016). Ferenczi. São Paulo: Casa do Psicólogo.

\footnotetext{
Notas:

${ }^{1} \mathrm{O}$ objetivo central deste texto começa a ganhar forma neste item, pois como ficará claro ao leitor, não pretendemos abordar as influências teóricas de Ferenczi sobre Klein, mesmo porque acreditamos que o maior influenciador de seu pensamento foi o seu segundo analista, Karl Abraham, cuja análise durou cerca de dois anos, sendo interrompida pela morte precoce de Abraham. Caso o leitor se interesse por essa discussão, recomendamos a leitura do artigo "Melanie Klein e Winnicott: porta-vozes das tradições de Abraham e Ferenczi" de autoria de Alfredo Naffah Neto, que foi publicado no livro "Melanie Klein na psicanálise contemporânea: teoria, clínica e cultura". Organizadoras: Cintra, E. M. U. \& Ribeiro, M. F. R. São Paulo: Zagodoni, 2019.

${ }^{2}$ A relação entre mãe filha foi sempre muito difícil. Melitta tornou-se, também, psicanalista, foi morar nos Estados Unidos, ao casar-se com um médico. Ao decorrer da vida, assumiu uma postura bastante questionadora (e até ofensiva) perante a obra teórica de sua mãe. As mágoas foram tantas, que Melitta se quer participou do velório de Klein em Londres.

${ }^{3}$ Revista Internacional de Psicanálise.
}

Citação/Citation: Almeida, A. P.; Naffah Neto, A. (2021). Sándor Ferenczi e Melanie Klein: a análise do analista como alicerce da formação. Trivium: Estudos Interdisciplinares (Ano XIII, Ed.2), pp. 92-102. 